
\title{
$\begin{array}{ll}\text { Research Square } & \begin{array}{l}\text { Preprints are preliminary reports that have not undergone peer review. } \\ \text { They should not be considered conclusive, used to inform clinical practice, } \\ \text { or referenced by the media as validated information. }\end{array}\end{array}$
}

\section{A Rhombencephalitis Revealing HIV Virorachia}

\section{Annick Melanie MAGNEROU ( $\nabla$ melanieannick@yahoo.fr)}

University of Douala

\section{Martine NIDA}

University of Douala Faculty of Medicine and Pharmaceutical Sciences: Universite de Douala Faculte de Medecine et Sciences Pharmaceutiques

\section{Daniel MASSI GAMS}

University of Buea Faculty of Health Sciences

\section{Hugues Martial ZANGA}

Douala Gynaeco-obstetric and Pediatric Hospital

\section{Fidelie Scolastique NGOUNGOURE HALIMA}

CH Perigueux: Centre Hospitalier de Perigueux

\section{Yacouba NJANKOUO MAPOURE}

University of Douala Faculty of Medicine and Pharmaceutical Sciences: Universite de Douala Faculte de Medecine et Sciences Pharmaceutiques

\section{Short report}

Keywords: Rhombencephalitis, HIV, ART, Virorachia

Posted Date: April 30th, 2021

DOl: https://doi.org/10.21203/rs.3.rs-465507/v1

License: @ (i) This work is licensed under a Creative Commons Attribution 4.0 International License. Read Full License 


\section{Abstract}

One of the possible causes of persistent inflammation of the brain parenchyma in the age of antiretrovirals is residual HIV replication, despite effective viral suppression in the bloodstream with Antiretroviral treatment (ART). The central nervous system (CNS) is infected early during primary HIV infection and is one of the reservoirs of this virus during chronic infection. Inadequate penetration of certain ART into the CNS could promote some degree of intrathecal HIV replication.

We describe the case of an HIV-infected patient compliant to ART with an undetectable viral load in the blood but present in the cerebrospinal fluid (CSF). The patient presented with subacute rhombencephalitis due to HIV which was fatal to him.

An HIV-infected and treated patient, well controlled on ART, with new neurological disorders, should be promptly investigated by brain MRI and CSF analysis for exhaustive detection of viruses including that of HIV itself.

\section{Introduction}

Serious neurological complications related to HIV has declined dramatically since the advent of effective antiretroviral treatment (ART). However neurological, and neurocognitive manifestations (the so-called 'HIV-associated neurocognitive disorders': HAND) remain relatively common among people living with HIV (PLWH), possibly related to chronic inflammation of the central nervous system (CNS) $(1,2)$. Although the causative role of HIV itself rather than other possible concomitant conditions is still debated (3).

The CNS is in fact infected early during the primary HIV infection and it is one of the reservoirs of this virus during chronic infection. The inadequate penetration of certain ART into the CNS could promote some degree of intrathecal HIV replication, or even the occurrence and selection of resistance mutations (4). But this phenomenon appears to be relatively rare and that it is explains only a fraction of the neurocognitive disorders in HIV-infected and treated patients. Indeed, the latter are sometimes affected by some comorbidities, which can alter the functioning of the CNS (5).

HIV Ribonucleic acid (RNA) Cerebrospinal fluid (CSF) escape is reported despite suppression of HIV RNA in the plasma compartment with effective ART $(4,6)$. CSF escape is a phenomenon in which HIV replication in the CNS overcomes the replication in the peripheral compartment (7).Sustained suppression of HIV RNA to clinically undetectable levels ( $<20$ copies $/ \mathrm{ml}$ ) in the plasma compartment with effective ART is achievable and results in restoration of immune system function in PLWH. As a consequence of this immune system function restoration, opportunistic diseases have now become rare in PLWH with access to effective ART and life expectancy approaches that of the general population (8).

\section{Definition:}


The HIV viral load is estimated by the amount of HIV RNA, determined by the reverse transcription polymerase chain reaction (RT-PCR), and is expressed in copies / $\mathrm{ml}$. Viremia is defined as the viral load present in the blood, while virorachia refers to that present in the CSF. When virorachia or viraemia are below the quantification threshold of the method used, they are said to be undetectable.

A mismatch between virorachia and viraemia, or "viral sanctuary effect of the CNS", or "HIV escape in the CSF" is defined by some authors as any detectable virorachia, that is greater than 200 copies / ml while the viremia is less than 50 copies / $\mathrm{ml}$, or like any virorachia 1 log greater than viraemia $(4,9)$. Nowadays, the limit of quantification is 20 copies / $\mathrm{ml}$ for blood and CSF in most centers.

\section{Physiopathology}

The mechanisms for HIV-induced neurological disease in treated patients can be explain by the limited diffusion of some ART through the blood-brain barrier and may allow HIV to persist and replicate at this level (10).

HIV infects the CNS early, that is, at the time of primary infection. The way the virus is transported there is still a matter of controversy. It could be transported by monocytes, lymphocytes or in the form of free viral particles (11). The hypothesis of monocytes serving as "Trojan horses" is supported by the fact that the viral strains isolated from the CNS have a CCR5 tropism and replicate efficiently in cultured macrophages. After crossing the blood-brain barrier, HIV appears to primarily infect macrophages in the brain parenchyma (microglial cells). It is also capable, but to a lesser extent, of infecting astrocytes (12). In contrast, neurons and oligodendrocytes are refractory to HIV infection. Replication of HIV in the CNS causes an inflammatory reaction characterized by the presence of numerous $C D 8+T$ lymphocytes with release of pro-inflammatory mediators as well as reactive astrocytosis. This inflammatory reaction is characteristic of HIV encephalopathy, itself generally associated with cognitive impairment(13). There does not appear to be a correlation between the severity of cognitive deficits and the HIV viral load in CSF (14). This suggests the important role of the cerebral inflammatory response secondary to viral replication, regardless of the magnitude of the latter.

\section{Case Report}

We present a case of 41-year-old man patient, known for HIV for 6 years, treated with TenofovirEmtricitabine-Efavirenz well adhering to the treatment with a good immuno-virological response. We noticed that two viremias carried out during the previous twelve months were undetectable and CD $4+T$ cell was at $600 / \mathrm{mm} 3$ six months before hospitalization. He presented with a subacute clinical presentation of fever, aphasia, left ptosis and left mydriasis associated with a confusional syndrome.

CT scan was done at the entry and didn't show any lesion and then the brain MRI was done and found mid-temporal, left mesencephalic, peri-mesencephalic hypersignals enhanced by contrast (Fig. 1).

CSF analysis revealed $0.4 \mathrm{~g} / \mathrm{L}$ of glycorachia, $0.6 \mathrm{~g} / \mathrm{L}$ of proteinorachia without leukorachia. The CSF test for cytomegalovirus, Epstein-Barr virus, Herpes simplex 1 and 2, Acid-alcohol-resistant bacilli, 
varicella-zoster virus by PCR, syphilis, cryptococcosis and soluble Antigen were negative. However, we found the presence of HIV RNA in the CSF by RT-PCR revealed 310 copies / $\mathrm{ml}$, for an undetectable viraemia (<30copies/ml). The CD4 + T cell count was actually at $334 / \mathrm{mm} 3$.

In front of the rapid worsening of the clinical picture, intravenous medication with Acyclovir $(10 \mathrm{mg} / \mathrm{kg} / 8$ hours), Ceftriaxone ( $2 \mathrm{~g} / 12$ hours) and corticosteroid (Dexamethasone $30 \mathrm{mg} / 24$ hours) therapy was initially initiated during the etiological investigation.

HIV viral rhombencephalitis by virological escape into the CNS compartment was retained in the absence of an alternative etiology; the ART had to be modified in order to improve its penetration into the brain, but the patient died after the 10th day of hospitalization.

\section{Discussion}

\section{Clinical}

There are various clinical pictures associated with an escape of the HIV in the CNS, there are often subacute and can have various clinical presentation as meningitis, encephalitis, or myelitis. Among the symptoms and signs reported, there is author who report persistent headache, cerebellar disorder, pyramidal syndromes, cognitive disorders, even an impairment of the state of consciousness (9). Our patient presented a progressive worsening of clinical picture in 5 days made of pyramidal syndrome, confusional syndrome and fever. The clinical vignette illustrates a particularly noisy case of virological escape at the level of the CNS. In India, Dravid et al. (15) found that out of the 1584 virologically suppressed individuals, 71 (4.4\%) patients had neurologic symptoms during follow-up and required inpatient care. Twenty of 71 (28.2\%) patients with neurologic clinical presentation had CSF/Plasma HIVRNA discordance. Imbalance during walking, tremor of hands, and forgetfulness were the most common presenting symptoms of patients presenting with discordance. Twelve of $20(60 \%)$ had subacute onset of symptoms. Canestri et al. (4) in his French series identified 11 chronically HIV-infected patients presenting with acute or subacute neurological symptoms, an active viral replication in CSF contrasting with suppressed plasma viremia, and a good immune status. Symptoms occurred subacutely in $8 / 11$ patients, whereas the clinical presentation was acute in the remaining $3 / 11$ patients. All patients were afebrile except 2 who had a low-grade fever (temperature $<38.5^{\circ} \mathrm{C}$ ).

\section{Brain imaging}

Faced with the clinical presentation of encephalic involvement in HIV-infected patient, an MRI was performed within 2 days of his admission in our hospital. The lesions found on imaging are those described in the literature: brain MRI reveals hyperintensities lesion in T2 and FLAIR at the level of the white substance. Most common MRI findings in patients with CSF/plasma HIV discordance in India series (15) were generalized cerebral atrophy and asymmetrical, non-enhancing periventricular white matter hyperintensities on T2 and FLAIR images. Three patients had HIV-related meningoencephalitis on MRI. Lesions tend to persist despite symptom resolution, lasting several months to several years $(4,9)$. 


\section{Biology}

On the series of Dravid et al. (15) median nadir CD4 count and median CD4 count at the time of discordance was 54.5 (IQR: 29.0-102.3) cells/mm3 and 352 (IQR: 200.3-505.8) cells/mm3, respectively. Median plasma and CSF VL in patients with CSF/plasma HIV discordance was 120 (IQR: $<20$ to 332.5) and 4250 (IQR: 2550.0-9615.0) copies/mL, respectively. Abnormal CSF studies (high CSF protein, abnormal CSF glucose, or lymphocytic pleocytosis) were found in 18 of 20 (95.0\%) patients. Median CSF protein was $97.5 \mathrm{mg} / \mathrm{dL}$ (IQR: 80.25-107.75), median CSF sugar was 54mg/dL (IQR: 45.75-56.50), and median CSF cell count was 18cells/mm3 (IQR: 10.0-35.0).

\section{Treatment}

In order to estimate the brain penetration of ART, a score was published by Letendre et al. in 2008 (16), and revised in 2010. He presented the ART brain penetration efficiency score called Cerebral penetration-effectiveness (CPE) ranking system (Table 1), established on the basis pharmacological studies at the CSF level, properties physicochemicals of molecules and their efficiency in terms of suppressing virorachia.

Table 1

Revised central system penetration effectiveness ranking by Letendre et al. (16)

\begin{tabular}{|c|c|c|c|c|}
\hline & CPE score & & & \\
\hline Antiretroviral drug class & 4 & 3 & 2 & 1 \\
\hline Nucleoside reverse transcriptase & Zidovudine & Abacavir & Didanosine & Tenofovir \\
\hline & & Emcitricitabine & Lamivudine & zalcitabine \\
\hline & & & stavudine & \\
\hline Nonnucleoside reverse & Nevirapine & Delavirdine & Etravirine & \\
\hline & & Efavirenz & & \\
\hline Protease inhibitors & Indinavir/r & Darunavir/r & Atazanavir & Nelfinavir \\
\hline & & Fosamprenavir/r & Atazanavir/r & Ritonavir \\
\hline & & Indinavir & Fosamprenavir & Saquinavir \\
\hline & & Lopinavir/r & & Saquinavir/r \\
\hline & & & & Tipranavir/r \\
\hline Entry/fusion inhibitors & & Maraviroc & & Enfuvirtide \\
\hline $\begin{array}{l}\text { Integrase strand transfer } \\
\text { inhibitors }\end{array}$ & & Raltegravir & & \\
\hline CPE :CNS penetration effectiver & & & & \\
\hline
\end{tabular}


In this system, ART are classified into four categories. The higher the score, the better the brain penetration of the drug. For combined treatment, the score of each molecule is added. High scores were associated with low virorachia as well as an upgrade cognitive functions in some $(5,9)$ Conversely, a low score was associated with an escape of HIV in the CSF(12). Our patient had rather low CPE scores on 7 , ART regimen took by our patient (Efavirenz, Tenofovir, Emcitricitabine) is the most frequently used ART regimen as describe by HIV causal collaboration (17) .

\section{Outcome}

The patient unfortunately died before his ART was changed. Vassalo et al.(18) and Ellis et al. (19)in their prospective studies investigating the effect of ART with a high CPE score on neurocognitive disorders associated with HIV have obtained discordant results. While the first (18) shows that patients receiving combined ART at a high CPE score were the most likely to be stable or improve their cognitive performance during the two years of follow-up, the second could not prove such a cause and effect relationship (19). More Prospective studies involving more subjects, a standardized battery of adequate neuropsychological tests and prolonged follow-up are therefore necessary to assess the impact of the optimization of the penetration of ART according to the CPE score on the control of virorachia and improvement of neurological and cognitive disorders.

\section{Conclusion}

Despite effective of ART treatment, PLWH can experience a wide array of difficult to manage neurologic complication. CSF/plasma HIV RNA discordance remains understudied in low-income settings such as Cameroon despite a substantial HIV burden. Identification and description of these specific patients can help to the growing body of African literature on this uncommon but increasingly significant topic.

\section{Abbreviations}

ART: Antiretroviral treatment.

CNS: central nervous system

CPE: Cerebral penetration-effectiveness

CSF: Cerebrospinal fluid

HAND: HIV-associated neurocognitive disorders

HIV : human immunodeficiency virus

PLWH: people living with HIV

RNA: Ribonucleic acid 


\section{Declarations}

Ethics approval and consent to participate: this work was carried out with respect for ethics and we have received the authorizations of the hospital and the families

Consent to publish: NA

Availability of data and materials:

Study material is available

\section{Competing interests:}

None of the authors has any conflict of interest to disclose.

\section{Funding:}

The study has not received any financial support.

\section{Authors' Contributions}

A.M. MAGNEROU: wrote the manuscript. M. NIDA: aided in interpreting the results and worked on the manuscript. D.G. MASSI and F.S.H. NGOUNGOURE: contributed to the analysis of the results and to the writing of the manuscript. H. M. ZANGA : a aided in interpreting the Imaging (CT Scan dans MRI) results and worked on the manuscript. Y.N. MAPOURE: supervised the findings of this work. All authors discussed the results and contributed to the final manuscript.

\section{Acknowledgements:}

We wish to thank to all the staff of the internal medicine department of the Douala Gynaeco-Obstetric and Pediatric Hospital for their help and collaboration.

\section{References}

\section{Reference:}

1. Robertson KR, Smurzynski M, Parsons TD, Wu K, Bosch RJ, Wu J, et al. The prevalence and incidence of neurocognitive impairment in the HAART era. AIDS. 2007 Sep;21(14):1915-21.

2. Antinori A, Arendt G, Becker JT, Brew BJ, Byrd DA, Cherner M, et al. Updated research nosology for HIV-associated neurocognitive disorders. Neurology. 2007 Oct;69(18):1789-99.

3. Gisslén M, Price RW, Nilsson S. The definition of HIV-associated neurocognitive disorders: are we overestimating the real prevalence? BMC Infect Dis. 2011 Dec;11:356.

4. Canestri A, Lescure F-X, Jaureguiberry S, Moulignier A, Amiel C, Marcelin AG, et al. Discordance between cerebral spinal fluid and plasma HIV replication in patients with neurological symptoms 
who are receiving suppressive antiretroviral therapy. Clin Infect Dis an Off Publ Infect Dis Soc Am. 2010 Mar;50(5):773-8.

5. Heaton RK, Clifford DB, Franklin DRJ, Woods SP, Ake C, Vaida F, et al. HIV-associated neurocognitive disorders persist in the era of potent antiretroviral therapy: CHARTER Study. Neurology. 2010 Dec;75(23):2087-96.

6. Edén A, Fuchs D, Hagberg L, Nilsson S, Spudich S, Svennerholm B, et al. HIV-1 viral escape in cerebrospinal fluid of subjects on suppressive antiretroviral treatment. J Infect Dis. 2010 Dec;202(12):1819-25.

7. Ferretti F, Gisslen M, Cinque P, Price RW. Cerebrospinal Fluid HIV Escape from Antiretroviral Therapy. Curr HIV/AIDS Rep. 2015 Jun;12(2):280-8.

8. May MT, Gompels M, Delpech V, Porter K, Orkin C, Kegg S, et al. Impact on life expectancy of HIV-1 positive individuals of CD4 + cell count and viral load response to antiretroviral therapy. AIDS. 2014 May;28(8):1193-202.

9. Peluso MJ, Ferretti F, Peterson J, Lee E, Fuchs D, Boschini A, et al. Cerebrospinal fluid HIV escape associated with progressive neurologic dysfunction in patients on antiretroviral therapy with well controlled plasma viral load. AIDS. 2012 Sep;26(14):1765-74.

10. Decloedt EH, Rosenkranz B, Maartens G, Joska J. Central nervous system penetration of antiretroviral drugs: pharmacokinetic, pharmacodynamic and pharmacogenomic considerations. Clin Pharmacokinet. 2015 Jun;54(6):581-98.

11. González-Scarano F, Martín-García J. The neuropathogenesis of AIDS. Nat Rev Immunol. 2005 Jan;5(1):69-81.

12. Spudich S, González-Scarano F. HIV-1-related central nervous system disease: current issues in pathogenesis, diagnosis, and treatment. Cold Spring Harb Perspect Med. 2012 Jun;2(6):a007120.

13. Lescure F-X, Moulignier A, Savatovsky J, Amiel C, Carcelain G, Molina J-M, et al. CD8 encephalitis in HIV-infected patients receiving cART: a treatable entity. Clin Infect Dis an Off Publ Infect Dis Soc Am. 2013 Jul;57(1):101-8.

14. Vitiello B, Goodkin K, Ashtana D, Shapshak P, Atkinson JH, Heseltine PN, et al. HIV-1 RNA concentration and cognitive performance in a cohort of HIV-positive people. AIDS. 2007 Jul;21(11):1415-22.

15. Dravid AN, Natrajan K, Kulkarni MM, Saraf CK, Mahajan US, Kore SD, et al. Discordant CSF/plasma HIV-1 RNA in individuals on virologically suppressive antiretroviral therapy in Western India. Medicine (Baltimore). 2018 Feb;97(8):e9969.

16. Letendre SL, Ellis RJ, Ances BM, McCutchan JA. Neurologic complications of HIV disease and their treatment. Top HIV Med. 2010;18(2):45-55.

17. Caniglia EC, Cain LE, Justice A, Tate J, Logan R, Sabin C, et al. Antiretroviral penetration into the CNS and incidence of AIDS-defining neurologic conditions. Neurology. 2014 Jul;83(2):134-41.

18. Vassallo M, Durant J, Biscay V, Lebrun-Frenay C, Dunais B, Laffon M, et al. Can high central nervous system penetrating antiretroviral regimens protect against the onset of HIV-associated 
neurocognitive disorders? AIDS. 2014 Feb;28(4):493-501.

19. Ellis RJ, Letendre S, Vaida F, Haubrich R, Heaton RK, Sacktor N, et al. Randomized trial of central nervous system-targeted antiretrovirals for HIV-associated neurocognitive disorder. Clin Infect Dis an Off Publ Infect Dis Soc Am. 2014 Apr;58(7):1015-22.

\section{Figures}

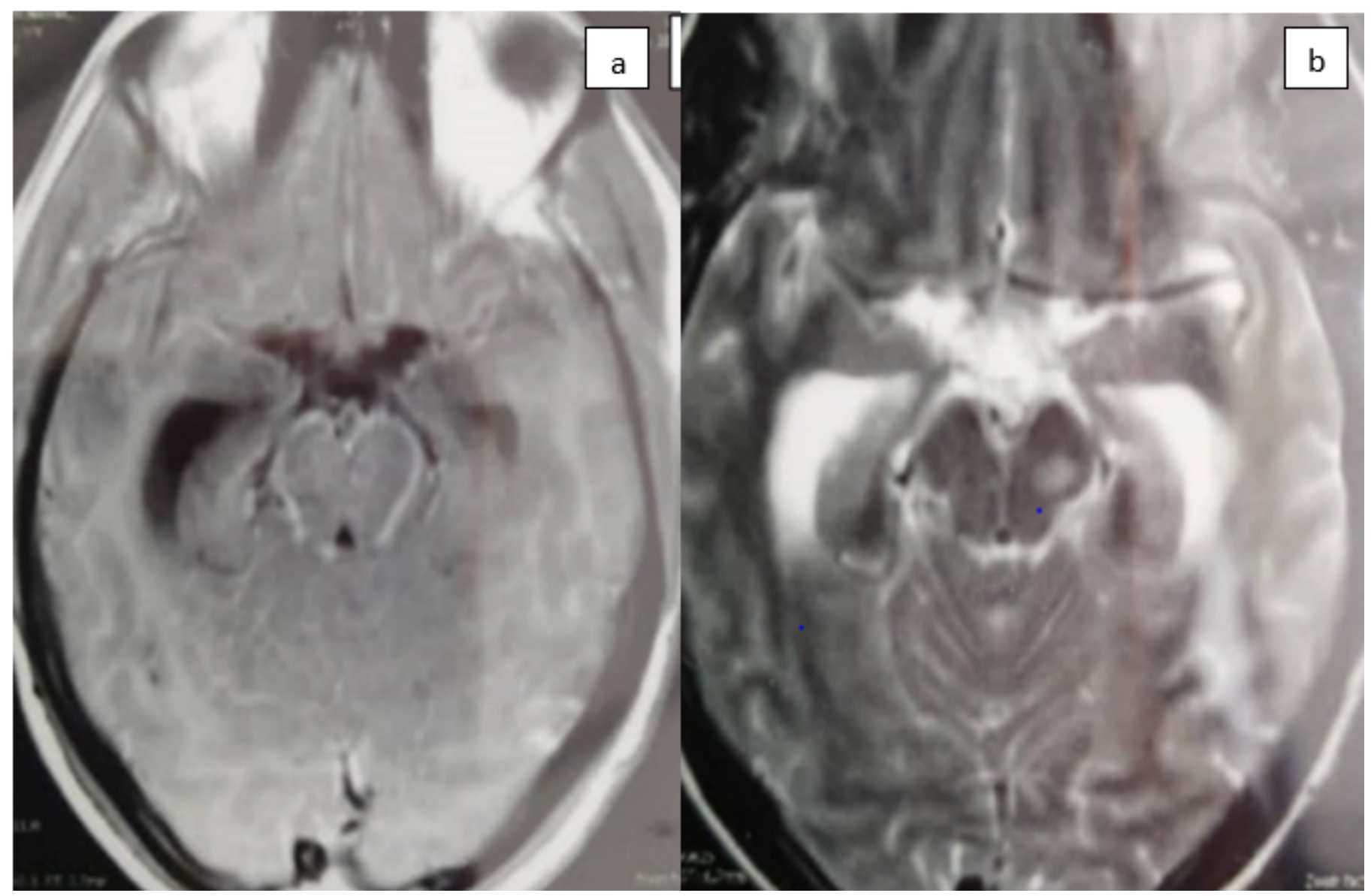

\section{Figure 1}

Cerebral MRI T1 peri-mesencephalic contrast enhancement (a) and left mesencephalic T Flair signal (b) 